\title{
Correlation between salivary and serum CA15-3 concentrations in patients with breast cancer
}

\author{
DANIELE XAVIER ASSAD ${ }^{1,2}$, ELISA CANÇADO PORTO MASCARENHAS ${ }^{1,3}$, \\ ANA GABRIELA COSTA NORMANDO ${ }^{1}$, HÉLÈNE CHARDIN ${ }^{4,5}$, \\ GUSTAVO BARCELOS BARRA ${ }^{6}$, RICCARDO PRATESI ${ }^{7}$, YANNA KARLA DE MEDEIROS NÓBREGA ${ }^{8}$, \\ ANA CAROLINA ACEVEDO ${ }^{1}$ and ELIETE NEVES SILVA GUERRA ${ }^{1}$
}

\begin{abstract}
${ }^{1}$ Laboratory of Oral Histopathology, Health Sciences Faculty, University of Brasília Campus Universitário Darcy Ribeiro, Brasília, DF 70910-900; ${ }^{2}$ Medical Oncology Department, Hospital Sírio-Libanês, Brasília, DF 70200-730; ${ }^{3}$ Department Medical Oncology, Cettro-Centro de Câncer de Brasília, Brasilia, DF 70710-904, Brazil; ${ }^{4}$ Department of Analytical, Bioanalytical Sciences and Miniaturization (LSABM), ESPCI Paris, PSL Research University, Paris 75005;

${ }^{5}$ Faculty of Dental Surgery, Paris Descartes Sorbonne Paris Cité University, Paris 92120 , France; ${ }^{6}$ Sabin Medicina Diagnóstica, Brasília, DF 70632-340; ${ }^{7}$ Interdisciplinary Laboratory of Biosciences and Celiac Disease Research Center, School of Medicine, University of Brasilia; ${ }^{8}$ Applied Analysis Laboratory, Department of Pharmaceutical Sciences, Health Sciences Faculty, University of Brasília, Brasília, DF 70910-900, Brazil
\end{abstract}

Received November 11, 2019; Accepted April 30, 2020

DOI: $10.3892 / \mathrm{mco} .2020 .2062$

\begin{abstract}
The early detection of breast cancer enables the use of less aggressive treatment and increases patient survival. The transmembrane glycoprotein mucin 1, which is also known as cancer antigen 15-3 (CA15-3), is aberrantly glycosylated and overexpressed in a variety of epithelial cancers, and serves a crucial role in the progression of the disease. CA15-3 is currently used as a marker of breast cancer. In the present study, CA15-3 concentrations in saliva and blood of patients with breast cancer were evaluated to test new assays to detect salivary CA15-3 in addition to ELISA and its diagnostic value. To the best of our knowledge, there are no previous reports of the use of chemiluminescence assay (CLIA) and electrochemiluminescence assay (ECLIA) in saliva. Saliva and blood were collected on the same day from patients with breast cancer $(n=26)$ and healthy controls $(n=28)$. For each subject, the level of serum CA15-3 was measured using ECLIA, and the level of salivary CA15-3 was measured using ECLIA, CLIA and enzyme-linked immunosorbent assay (ELISA). ELISA and CLIA were able to detect CA15-3 in saliva; however, ECLIA could not detect salivary CA15-3. There was no significant difference between the mean serum and salivary CA15-3 levels in patients with breast cancer
\end{abstract}

Correspondence to: Professor Eliete Neves Silva Guerra, Laboratory of Oral Histopathology, Health Sciences Faculty, University of Brasília Campus Universitário Darcy Ribeiro, Brasília, DF 70910-900, Brazil

E-mail: elieteneves.unb@gmail.com

Key words: breast cancer, cancer antigen 15-3, saliva, chemiluminescence assay, electrochemiluminescence assay or healthy controls. The levels of CA15-3 were highest for luminal breast cancer subtypes and stage IV cases. A moderate correlation was observed between salivary and serum CA15-3 levels as measured by ELISA in breast cancer patients $(\mathrm{r}=0.56$; $\mathrm{P}=0.0047$ ). The results demonstrated that ECLIA was not a good method to detect salivary CA15-3, although it is the gold standard for detecting serum CA15-3. The presence of CA15-3 in saliva was confirmed, and this will be useful in future research. Further investigations are necessary to confirm the ability to detect salivary CA15-3 and its correlation with serum CA15-3.

\section{Introduction}

Breast cancer is the most commonly diagnosed cancer and the leading cause of cancer death among females (1). A multidisciplinary approach involving surgical, radiation, and systemic treatments has contributed to a reduction in breast cancer mortality in recent years. Probably, the reduction is mainly due to better breast cancer screening and adjuvant therapy (2).

The early diagnosis of breast cancer is vital to increase survival rates, decrease morbidity, and reduce the likelihood of recurrence of disease (3). When breast cancer is diagnosed at an early stage, treatments are more successful than when the initial tumor burden is advanced (4).

Breast cancer diagnosis involves identification of a suspected lesion with radiological screening, and a confirmatory biopsy (3). Conventional screening with physical examination and mammography has less-than-desirable sensitivity (54\%) and specificity (77\%) (5). Breast biopsy and histopathology studies are the reference standard for diagnosis, but the procedure is invasive and carries a risk of morbidity (6).

In normal secretory epithelial cells, MUC1 localizes in the apical membrane and provides protection to the underlying epithelia in healthy tissues, maintaining homeostasis, and 
promoting cell survival in variable conditions (7). In contrast, tumor-associated MUC1 participates in intracellular signal transduction pathways and regulates the expression of its target genes at both the transcriptional and posttranscriptional levels (8).

Cancer antigen 15-3 (CA15-3) is a soluble form of MUC1. CA15-3 corresponds to an immunodominant epitope in the extracellular portion of the protein that is shed into the bloodstream and can be detected by several monoclonal antibodies (9). CA15-3 is the most widely used serum marker to detect recurrent breast cancer and monitor treatment of patients with advanced disease (10).

Saliva offers several benefits over traditional blood-based biochemical analyses for clinical diagnostics: Non-invasiveness and stress-free sample collection; easy and multiple sampling opportunities; reduced need for sample pre-processing; minimal risk of contracting infectious organisms (11). Saliva has recently emerged as a source of biochemical data to detect chronic diseases, as it may contain real-time information describing the overall physiological condition (12).

Enzyme-linked immunosorbent assay (ELISA), electrochemiluminescence (ECLIA), and chemiluminescence (CLIA) are the methods typically used to assess serum levels of CA15-3 (13,14). For evaluating salivary levels of CA15-3, the most frequently reported method is ELISA (13) and there are no reports of the application of CLIA or ECLIA. There is a need to evaluate alternative methods for detecting salivary levels of CA15-3.

In this study, ECLIA was performed to assess serum levels of CA15-3 in all subjects. In addition, ELISA, CLIA, and ECLIA were used to quantify and compare CA15-3 levels in the saliva of breast cancer patients and in healthy controls. Because serum CA15-3 is the most commonly used serum marker in breast cancer patients, the search for salivary CA15-3 measurement techniques becomes interesting, because it is less invasive in patients who usually have many venipuncture exams.

\section{Patients and methods}

Subjects. Subject recruitment and sample collection followed the guidelines of the Institutional Review Board of the oncology recruiting centers: Hospital Universitário de Brasília (HUB), Hospital de Base do Distrito Federal (HBDF), Hospital Sírio Libanês and Cettro. The cohort study was approved by the Research Ethics Committee of the Faculty of Health Sciences, University of Brasilia (Brasilia, Brazil; Plataforma Brasil protocol 57449716.5.0000.0030), and was conducted according to the Declaration of Helsinki principles. Written informed consent was obtained from each subject before participation in the study. Patients and healthy controls were recruited between October 2017 and April 2018.

The inclusion criteria for the breast cancer patients group were as follows: i) Capable of giving informed consent; ii) not pregnant or lactating; iii) no active oral/dental disease; iv) no prior neoplasia (except for non-melanomatous skin cancers and carcinoma in situ of the cervix, or benign tumors such as adenomas), and no alterations of renal function, congestive heart failure, active infection hepatitis or HIV; and v) a proven histopathologic diagnosis of breast cancer. These patients were enrolled prior to excision of the primary tumor and systemic treatment (neo-adjuvant chemotherapy or palliative endocrine/or chemotherapy). We excluded patients and healthy controls if they showed signs of morbidity and health problems such as autoimmune disease, HIV, impaired renal function, congestive heart failure, active infection and hepatitis. All patients were recruited by convenience after appointment at an oncology center. The control subjects were healthy female volunteers recruited from the general population, for whom breast cancer was ruled out by physical examination and radiological breast images. None of the participants in the control group were knowingly suffering or being treated for a malignancy. The study was not blinded.

Specimen collection, transportation, and preparation. Venous blood and saliva samples were collected on the same day for each participant. All participants abstained from eating, drinking, smoking, and performing oral hygiene procedures for at least $1 \mathrm{~h}$ prior to collection of saliva. Participants were instructed to chew on a cotton swab (Salivette ${ }^{\circledR}$; SARSTEDT AG \& Co.) for a period of $2 \mathrm{~min}$. Each swab containing saliva was returned to a separate plastic container and then packaged in styrofoam with recyclable ice sheets. Within $4 \mathrm{~h}$, the material was transported to the laboratory for processing. The saliva sample was centrifuged at $3,600 \mathrm{~g} \mathrm{x} 5 \mathrm{~min}$ at $8^{\circ} \mathrm{C}$. After centrifugation, the sample was transferred to a clean Eppendorf tube and frozen at $-80^{\circ} \mathrm{C}$ until processing. The saliva samples were thawed at room temperature for CA15-3 analysis. Typically, patients donated 5-10 $\mathrm{ml}$ of saliva.

Blood samples were obtained by venipuncture and were collected in serum tubes with separator gel. Blood was centrifuged at 3,500-5,000 rpm for $5 \mathrm{~min}$ and the total volume obtained was separated into 2 Eppendorf tubes and frozen at $-20^{\circ} \mathrm{C}$ prior to analysis.

ECLIA for detection of serum and salivary CA15-3. Measurement of serum CA15-3 was performed by ECLIA on a fully automated Roche Cobas 8000 analyzer with an e801 module (Roche Diagnostics) according to the manufacturer's instructions, and reported in $\mathrm{U} / \mathrm{ml}$. The limit of blank, limit of detection, and limit of quantification for measuring CA15-3 in serum with the Cobas e801 module are 1.0, 1.5 and $3 \mathrm{U} / \mathrm{ml}$, respectively (Elecsys CA15-3 II Label, cat. no. 07027001500V2.0; Roche Diagnostics).

Measurement of salivary CA15-3 was performed as described above for serum; however, saliva is an off-label specimen for the applied assay.

CLIA for detection of salivary CA15-3. Measurement of salivary CA15-3 was performed according to the manufacturer's instructions using a sandwich CLIA with the BR-MA 15-3 reagent kit in an IMMULITE $1000^{\circledR}$ system (Siemens Healthcare Diagnostics Inc.). The kit for serum assay was used for salivary assay; however, saliva is an off-label specimen for the applied assay. There is no kit designed for use with saliva.

The microtiter plates were pre-coated with an antibody specific for the analyte. Standards or samples were added to the appropriate microtiter plate wells, where the analyte present in the standards and samples would bind to the immobilized antibody. Next, biotin-conjugated antibody was added and bound 
to the analyte on the plate. The complex of two antibodies and the analyte in the wells forms a 'sandwich' structure. After any unbound biotin-conjugated antibody was removed by washing, avidin-conjugated horseradish peroxidase was added to each microplate well. After incubation at $25^{\circ} \mathrm{C}$ for $20 \mathrm{~min}$, luminol was added into the wells. Relative luminescence intensity was determined using a photomultiplier, in relative light units (RLU), being proportional to the amount of CA15-3 present in the sample, and the results were expressed as $\mathrm{U} / \mathrm{ml}$. The assay limit of detection for CA15-3 is $1.0 \mathrm{U} / \mathrm{ml}$ (14).

ELISA for detection of salivary CA15-3. ELISA reactions were performed using the CA15-3 AccuBind ${ }^{\mathrm{TM}}$ reagent kit (Lake Forest, California, United States of America) for use in BEST $2000^{\circledR}$ equipment (Biokit S.A.), according to the manufacturer's instructions. The kit used for saliva was the same as that used for serum; however, saliva is an off-label specimen. The absorbance was read at $450 \mathrm{~nm}$ using a spectrophotometer and concentrations were calculated from standard curves constructed from known concentrations of the ligand.

For the calculation of the results, a standard-logarithmic curve was obtained by plotting the measured values of the 6 calibrators by the corresponding units (linear/log). The analysis was performed in duplicate, and the mean of the two values obtained was calculated. The results were expressed as $\mathrm{U} / \mathrm{ml}$.

For this assay, the limit of blank and functional limit of detection for measuring CA15-3 in serum are $0.2 \mathrm{U} / \mathrm{ml}$ and $1.25 \mathrm{U} / \mathrm{ml}$, respectively (AccuBind ${ }^{\mathrm{TM}}$ reagent kit, Revision: 3 , Date: 072611, cat. no. 5625-300, DCO:0504; Monobind Inc.).

TNM (tumor, node, metastasis staging system) and molecular profile of breastcancer. TNM staging was performed according to the 7th edition of the AJCC (15), and the molecular profile classification was determined in accordance with the immunohistochemical definitions of the Saint Gallen consensus (16). The mean levels of serum and salivary CA15-3, detected by ECLIA, CLIA, and ELISA, were determined for each patient based on TNM and molecular profile.

Statistical analysis. Statistical analysis was performed using SAS 9.4 version 9.4 (SAS Institute Inc.). Student's t tests and Chi-square/Fisher's exact tests were applied to demographic and clinical characteristics. A Mann-Whitney U test was used to determine differences between mean values of serum and salivary CA15-3 among controls and breast cancer patients. A Kruskal-Wallis test was used to compare mean values of salivary CA15-3 and serum CA15-3 among molecular subtypes and stages, and, when $\mathrm{P} \leq 0.05$, multiple comparisons were implemented using the Dwass, Steel, Critchlow-Fligner (DSCF) method. Correlations between serum and salivary CA15-3 in controls and breast cancer patients were assessed using Pearson correlation coefficients. Values of $\mathrm{P}<0.05$ were considered statistically significant.

\section{Results}

Table I summarizes the characteristics of the 28 control subjects and 26 breast cancer patients. The mean age of the controls was lower than breast cancer patients
(37.64+/-13.57 years vs. 48.23+/-11.51 years, $\mathrm{P}=0.0033)$. There were more postmenopausal women among breast cancer patients than in the controls ( 11 vs. $4, \mathrm{P}=0.0216)$. There was no significant difference between the healthy controls and cancer patients regarding tobacco use, medication use, and presence of systemic disorders $(\mathrm{P}=0.1842, \mathrm{P}=0.5541$, and $\mathrm{P}=0.8473$, respectively). Mean body mass index was significantly higher in breast cancer patients than in controls $(\mathrm{P}=0.0184)$.

There were two cases at stage I (7\%), ten (39\%) at stage IIa, three $(12 \%)$ at stage IIb, four $(15 \%)$ at IIIb, one (3\%) at stage IIIc and five $(23 \%)$ at stage IV breast cancer cases. There were three (11.5\%) luminal B-like HER2 negative, seven (27\%) luminal A-like, five (19\%) HER2 positive (nonluminal), four (15\%) luminal B-like HER2 positive, and five (19\%) triple negative breast cancer cases. There was no information for TNM in one patient and for the molecular profile in two patients. The complete subject information is listed in Table SI.

Serum (ECLIA) and salivary (CLIA and ELISA) values of CA15-3 for each subject are listed in Table SI. Salivary CA15-3 was undetected by ECLIA. Mean serum CA15-3 by ECLIA was $134 \pm 369.00 \mathrm{U} / \mathrm{ml}$ in breast cancer patients and $15.73 \pm 6.18 \mathrm{U} / \mathrm{ml}$ in healthy controls, $\mathrm{P}=0.06$ (Table II). Although ECLIA is considered the reference test to evaluate CA15-3 in blood, it showed a wide variation in measurements between patients, generating a large standard deviation.

Mean salivary CA15-3 by CLIA was $4.73 \pm 5.74 \mathrm{U} / \mathrm{ml}$ in breast cancer patients and $6.51 \pm 7.18 \mathrm{U} / \mathrm{ml}$ in healthy controls, $\mathrm{P}=0.18$. Mean salivary CA15-3 measured by ELISA was $1.77 \pm 1.08 \mathrm{U} / \mathrm{ml}$ in breast cancer patients and $1.83 \pm 2.09 \mathrm{U} / \mathrm{ml}$ in healthy controls, results confirm that serum CA15-3 values are higher in breast cancer patients results confirm that serum CA15-3 values are higher in breast cancer patients. Either the ECLIA assay was not able detect the CA15-3 protein in saliva or the CA15-3 levels in saliva were below the ECLIA limit of detection $(1.5 \mathrm{U} / \mathrm{ml})$. The CLIA and ELISA limits of detection were $1.0 \mathrm{U} / \mathrm{ml}$ and $1.25 \mathrm{U} / \mathrm{ml}$, respectively, hence ECLIA was the least sensitive among the tested assays. There was no significant difference between serum CA15-3 levels in breast cancer patients and healthy women $(\mathrm{P}=0.06)$. There was no difference in salivary CA15-3 concentration between breast cancer cases and controls when measured by CLIA $(\mathrm{P}=0.18)$ and ELISA $(\mathrm{P}=0.55)$.

Table III shows the CA15-3 concentrations in saliva and serum according to breast cancer molecular subtypes. The analysis was performed in 24 patients with a known molecular profile. There was no difference in mean concentration values for serum CA15-3 measured by ECLIA $(P=0.20)$, salivary CA15-3 measured by ELISA $(\mathrm{P}=0.70)$ and CLIA $(\mathrm{P}=0.78)$ according to molecular subtype. ECLIA for serum CA15-3 revealed the highest values for luminal A subtype, with 269.47 $\pm 659.97 \mathrm{U} / \mathrm{ml} \mathrm{CA15-3}$ concentration. The highest values for CA15-3 mean concentration in luminal B HER2+ subtype were $2.58 \pm 1.83 \mathrm{U} / \mathrm{ml}$ with ELISA and $10.57 \pm 11.74 \mathrm{U} / \mathrm{ml}$ with CLIA.

Table IV shows the CA15-3 mean concentrations in saliva and serum according to TNM stages. The analysis was performed in 25 patients with known TNM stage. There was no difference in salivary CA15-3 by ELISA $(\mathrm{P}=0.44)$ and CLIA $(\mathrm{P}=0.40)$ among different breast cancer stages. Serum 
Table I. Demographic data based on participants records.

\begin{tabular}{|c|c|c|c|}
\hline Characteristics $^{\mathrm{a}}$ & Healthy control $(n=28)$ & Breast cancer $(n=26)$ & P-value ${ }^{b}$ \\
\hline Age & $37.64 \pm 13.57$ & $48.23 \pm 11.51$ & $<0.01$ \\
\hline Body mass index & $22.93 \pm 3.14$ & $25.39 \pm 4.25$ & 0.02 \\
\hline Menopause status & & & 0.02 \\
\hline Pre-menopause & $24(85.71)$ & $15(57.69)$ & \\
\hline Menopause & $4(14.29)$ & $11(42.31)$ & \\
\hline Tobacco use & & & 0.18 \\
\hline No & $27(96.43)$ & $19(84.62)$ & \\
\hline Yes & $1(3.57)$ & $4(15.38)$ & \\
\hline Use of medication & & & 0.55 \\
\hline No & $15(53.57)$ & $16(61.54)$ & \\
\hline Yes & $13(46.43)$ & $10(38.46)$ & \\
\hline Systemic disease & & & 0.85 \\
\hline No & $19(67.86)$ & $17(65.38)$ & \\
\hline Yes & $9(32.14)$ & $9(34.62)$ & \\
\hline
\end{tabular}

${ }^{a}$ Mean values \pm standard deviation, or frequency $(\%)$; ${ }^{b}$ Student's $t$ test and $\chi^{2} /$ Fisher's exact test.

Table II. Serum and salivary CA15-3 mean concentration \pm standard deviation for healthy controls and patients with breast cancer.

\begin{tabular}{lccc}
\hline Method & Healthy control $(\mathrm{n}=28)$ & Breast cancer $(\mathrm{n}=26)$ & $\mathrm{P}_{\text {-value }}$ \\
\hline ECLIA Serum $(\mathrm{U} / \mathrm{ml})$ & $15.73 \pm 6.18$ & $134 \pm 369$ & 0.06 \\
CLIA Salivary $(\mathrm{U} / \mathrm{ml})$ & $6.51 \pm 7.18$ & $4.73 \pm 5.74$ & 0.19 \\
ELISA Salivary $(\mathrm{U} / \mathrm{ml})$ & $1.83 \pm 2.09$ & $1.77 \pm 1.08$ & 0.56
\end{tabular}

${ }^{a}$ Mann-Whitney U test; ECLIA, electrochemiluminescence assay; CLIA, chemiluminescence assay; ELISA, enzyme-linked immunosorbent assay.

Table III. CA15-3 mean concentration values \pm standard deviation according to breast cancer molecular subtype.

\begin{tabular}{lcccrrr}
\hline Method & Luminal A & Luminal B HER2+ & Luminal B HER2- & HER2 positive & Triple negative $^{\text {P-value }}{ }^{\mathrm{a}}$ \\
\hline ECLIA Serum (U/ml) & $269.47 \pm 659.97$ & $141.60 \pm 183.22$ & $196.90 \pm 186.53$ & $18.04 \pm 7.98$ & $14.98 \pm 6.87$ & 0.20 \\
ELISA Salivary (U/ml) & $1.71 \pm 1.11$ & $2.58 \pm 1.83$ & $1.61 \pm 0.33$ & $1.97 \pm 1.27$ & $1.28 \pm 0.26$ & 0.70 \\
CLIA Salivary (U/ml) & $4.13 \pm 5.25$ & $10.57 \pm 11.74$ & $3.43 \pm 3.03$ & $2.72 \pm 1.14$ & $5.65 \pm 5.44$ & 0.78 \\
\hline
\end{tabular}

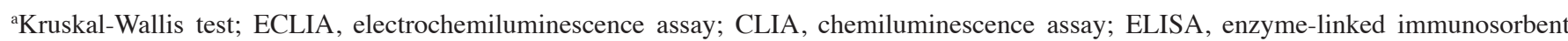
assay; CA15-3, cancer antigen 15-3.

CA15-3 levels were significantly different in at least two stages of breast cancer $(\mathrm{P}=0.01)$. The DSCF multiple comparison test revealed differences in serum CA15-3 concentrations among stage IV and stage IIa cases. The mean serum CA15-3 value for stage IV cases $(508.20 \pm 718.32 \mathrm{U} / \mathrm{ml})$ was higher than that for stage IIa $(17.18 \pm 9.14 \mathrm{U} / \mathrm{ml})(\mathrm{P}=0.03)$. There were no other significant differences in mean serum CA15-3 values between stages. In all analyses in both serum and saliva, the TNM stage IV disease cases showed the highest mean CA15-3 concentration: $508.20 \pm 718.32 \mathrm{U} / \mathrm{ml}$ with ECLIA in serum,
$2.73 \pm 1.82 \mathrm{U} / \mathrm{ml}$ with ELISA in saliva, and $7.78 \pm 9.70 \mathrm{U} / \mathrm{ml}$ with CLIA in saliva.

Among breast cancer cases, there was a significant positive correlation of serum CA15-3 and salivary CA15-3 with ELISA ( $\mathrm{r}=0.56 ; \mathrm{P}=<0.01)$; however no significant correlation of salivary CA15-3 and serum CA15-3 was observed with CLIA ( $\mathrm{P}=0.19)$ Among healthy controls, the correlations of salivary CA15-3 with serum CA15-3 according to CLIA and ELISA were not significant $(\mathrm{P}=0.77$ and $\mathrm{P}=0.35$ respectively). All correlations are shown in Fig. 1. Fig. 1 shows that in breast 
Table IV. Mean CA15-3 concentration values \pm standard deviation according to TNM stage.

\begin{tabular}{|c|c|c|c|c|c|c|}
\hline Method & $\mathrm{I}$ & II $\mathrm{a}^{\mathrm{a}}$ & II $b^{a}$ & III $b^{a}$ & $\mathrm{IV}^{\mathrm{a}}$ & P-value ${ }^{a}$ \\
\hline ECLIA Serum (U/ml) & $16.50 \pm 11.31$ & $17.18 \pm 9.14$ & $15.00 \pm 5.43$ & $97.13 \pm 100.13$ & $508.20 \pm 718.32$ & 0.01 \\
\hline ELISA Salivary (U/ml) & $1.41 \pm 0.19$ & $1.77 \pm 0.98$ & $1.46 \pm 0.22$ & $1.28 \pm 0.13$ & $2.73 \pm 1.82$ & 0.45 \\
\hline CLIA Salivary (U/ml) & - & $4.00 \pm 3.18$ & $3.50 \pm 1.56$ & $1.25 \pm 0.21$ & $7.78 \pm 9.70$ & 0.40 \\
\hline
\end{tabular}

${ }^{a}$ Kruskal-Wallis test, and Dwass, Steel, Critchlow-Fligner multiple comparisons test of (DSCF). Comparison of stages IIa and IV (P=0.03). ECLIA, electrochemiluminescence assay; CLIA, chemiluminescence assay; ELISA, enzyme-linked immunosorbent assay; TNM, tumor node metastasis; CA15-3, cancer antigen 15-3.
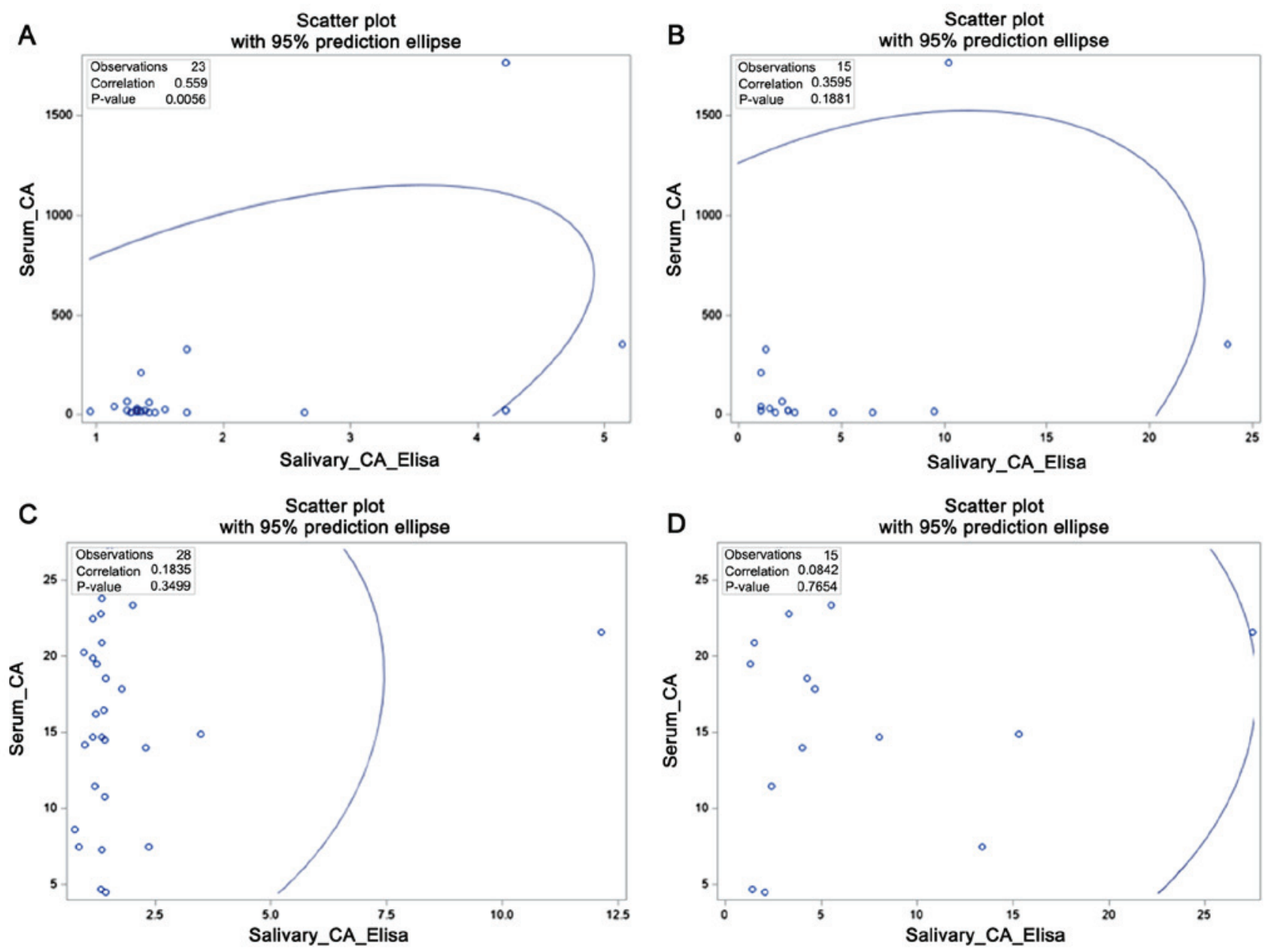

Figure 1. Correlations of serum and salivary CA15-3. (A) Correlation curve of serum CA15-3 and salivary CA15-3 as detected by ELISA in patients with breast cancer $(\mathrm{r}=0.56 ; \mathrm{P}=<0.01)$. (B) Correlation curve of serum CA15-3 and salivary CA15-3 as detected by CLIA in patients with breast cancer ( $\mathrm{r}=0.36$; $\mathrm{P}=0.19$ ). (C) Correlation curve of serum CA15-3 and salivary CA15-3 as detected by ELISA in healthy controls ( $\mathrm{r}=0.18$; $\mathrm{P}=0.35$ ). (D) Correlation curve of serum CA15-3 and salivary CA15-3 as detected by CLIA in healthy controls $(\mathrm{r}=0.08 ; \mathrm{P}=0.77)$. ELISA, enzyme-linked immunosorbent assay; CLIA, chemiluminescence assay; CA15-3, cancer antigen 15-3.

cancer patients (Fig. 1A and B), there is a growing linear relationship, with statistical difference with ELISA (Fig. 1A). Otherwise, in the control group (Fig. 1C and D), there is random distribution of points without linear relationship.

\section{Discussion}

Previous studies have reported detection of salivary CA15-3 with ELISA but not with ECLIA and CLIA (13). We chose to evaluate detection of CA15-3 using CLIA and ECLIA because these techniques are used routinely in clinical exams for evaluation of serum tumor markers and serology of viral infectious agents (17). Recently, CLIA was used to evaluate proteins in liquor, demonstrating that the method can be used to analyze different fluids, such as saliva (17). ECLIA and CLIA do not require long incubations or the addition of stopping reagents, so they have superior low-end sensitivity, and are faster than conventional colorimetric assays such as ELISA. 
Several hypothetical mechanisms have been suggested to explain the presence of large molecules such as CA15-3 in saliva. The proposed hypothesis is that active transport of proteins into saliva by the salivary glandular epithelium could explain the presence of membrane-bound proteins such as CA15-3. In breast cancer patients, there would be an overabundance of various bioactive proteins associated with the rapid, abnormal growth of the neoplasm, which in turn could produce a response in the salivary glands (18). Further studies are necessary to better understand the regulatory mechanisms of elevated salivary CA15-3 in breast cancer patients.

Luminal subtype breast cancer shows a higher expression of MUC1 genes and a positive relationship between MUC1 and estrogen receptor (ER) gene expression has been reported (19). Park et al reported higher values for CA15-3 in luminal subtypes of tumor than in other subtypes (20). Our results showed the highest values for serum and salivary CA15-3 for luminal subtypes of breast cancer. As shown in Table III, the molecular subtype of breast cancer luminal A presented the highest standard deviation. This result may be due to the inclusion of a patient with metastatic breast cancer with serum CA15-3 of 1,766.0 U/ml. This patient also had CA15-3 concentrations in the saliva of $10.2 \mathrm{U} / \mathrm{ml}$ according to CLIA and $4.22 \mathrm{U} / \mathrm{ml}$ according to ELISA.

In many tumor types, MUC1 expression correlates with aggressive, metastatic disease, poor response to therapy, and poor survival (21). MUC1 expression is seen in all subtypes of breast cancer, including luminal, HER2, and basal, although in each of these cancer types, expression is highest in tumors that have metastasized (21). The detection of CA15-3 in patient sera is currently used as a marker of response to therapy and as a prognostic indicator for survival, with high CA15-3 levels correlating with higher grade tumors, lymph node involvement, and presence of distant metastases in breast cancer (22). Emens et al showed that the concentration of serum CA15-3 increases with increasing TNM stage, with $9 \%$ of stage I, 19\% of stage II, $38 \%$ of stage III, and $75 \%$ of stage IV cases showing abnormal serum CA15-3 concentrations (23). In our samples, stage IV disease was related to the greatest mean values of CA15-3 in serum and saliva when compared with the earlier stages of disease (1-3).

In the present study, a moderate association was found between serum and salivary CA15-3 in breast cancer patients using ELISA ( $\mathrm{r}=0.56 ; \mathrm{P}=<0.01)$. Agha-Hosseini et al found that salivary and serum levels of CA15-3 were significantly higher in cancer patients, with a significant positive correlation between serum and saliva CA15-3 concentrations (24). Streckfus $e t$ al also reported a moderate correlation between salivary and serum CA15-3 concentration with ELISA (18).

Serum CA15-3 is an invasive exam requiring venipuncture in patients who usually have fragile veins due to previous chemotherapy and excessive routine blood tests. Salivary methods for protein detection would allow evaluation without pain and discomfort to the patient and could therefore provide a more convenient alternative to CA15-3 serum assays (25). Salivary CA15-3 could also be an interesting test for cancer screening in general population, specially for the luminal subtypes of breast cancer because of the relationship of MUC-1 and estrogen receptor. The possibility of biomarkers using cancer derived saliva exosomes is attractive because of the stability of vesicles in blood and fluids (26). Saliva has already been widely used in genetic testing (27) owing to its better transport stability compared to that of blood (28). In addition, knowledge regarding whether proteins and tumor DNA are present in other fluids aids in our understanding of the biological behavior of the disease.

Although there was no statistical difference, there is a tendency for higher serum CA15-3 values in breast cancer patients. There is a tendency for higher salivary CA15-3 values in controls compared to breast cancer patients. The main limitations of the study are: Sample size, unbalanced age groups and menopausal status. Reduced sample size and lack of standardized kits for saliva CA15-3 evaluation may have contributed to inconsistent salivary CA15-3 results in controls. ECLIA was not a good method to detect salivary CA15-3, although it is the reference standard for detecting serum CA15-3. Importantly, the CA15-3 kit used for ECLIA of saliva is standardized for blood; this may have contributed to the poor detection of CA15-3 in saliva, as these fluids have different conductivities, and antibodies may have different sensitivities and affinities in different body fluids. In breast cancer patients, we observed a correlation between serum and salivary CA15-3 detected by ELISA. CA15-3 concentrations were highest in stage IV and luminal breast cancer subtypes. The study shows that CA15-3 was detected in saliva with ELISA and CLIA, but not with the ECLIA reference technique for detecting serum CA15-3. New studies evaluating the detection of CA15-3 in saliva may allow this marker to be used in the follow up of breast cancer patients, who often have their venous network compromised due to successive puncture exams. Further investigations are needed to confirm the capability of detection of salivary CA15-3 and its correlation to serum CA15-3.

\section{Acknowledgements}

Not applicable.

\section{Funding}

This work was supported by grants from the Fundação de Apoio à Pesquisa do Distrito Federal (FAPDF, Brasília, Brazil). Grant no. 00193.00001319/2018-33.

\section{Availability of data and materials}

The datasets used and/or analyzed during the present study are available from the corresponding author on reasonable request.

\section{Authors' contributions}

DXA, ECPM, ACA, ENSG and HC conceived or designed the study. DXA, AGCN, ECPM, ACA, ENSG, and AC performed the research. DXA, ENSG, GBB, YKMN, RP and AC analyzed the data. GBB and YKMN contributed with new methods or models. DXA, ACA, ENSG, ECPM and AGCN wrote the paper. ACA, ENSG supervised the research. All authors read and approved the final manuscript. 


\section{Ethics approval and consent to participate}

The study was approved by the Research Ethics Committee of the Faculty of Health Sciences, University of Brasilia (Brasilia, Brazil; Plataforma Brasil protocol 57449716.5.0000.0030), and was conducted according to the Declaration of Helsinki principles. Written informed consent was obtained from each subject before participation in the study.

\section{Patient consent to publication}

Written informed consent was obtained from each subject before participation in the study, the informed consent included consent for publication of the data and clinical information.

\section{Competing interests}

The authors declare that they have no competing interests.

\section{References}

1. Bray F, Ferlay J, Soerjomataram I, Siegel RL, Torre LA and Jemal A: Global cancer statistics 2018: GLOBOCAN estimates of incidence and mortality worldwide for 36 cancers in 185 countries. CA Cancer J Clin 68: 94-424, 2018.

2. Narod SA, Iqbal J and Miller AB: Why have breast cancer mortality rates declined? J Cancer Policy 5: 8-17, 2015.

3. Arellano M, Jiang J, Zhou X, Zhang L, Ye H, Wong DT and Hu S: Current advances in identification of cancer biomarkers in Saliva. Front Biosci (Schol Ed) 1: 296-303, 2009.

4. Giuliano AE, Connolly JL, Edge SB, Mittendorf EA, Rugo HS, Solin LJ, Weaver DL, Winchester DJ and Hortobagyi GN: Breast cancer-major changes in the American joint committee on cancer eighth edition cancer staging manual. CA Cancer J Clin 67: 290-303, 2017.

5. Berg WA, Gutierrez L, NessAiver MS, Carter WB, Bhargavan M, Lewis RS and Ioffe OB: Diagnostic accuracy of mammography, clinical examination, US, and MR imaging in preoperative assessment of breast cancer. Radiology 233: 830-849, 2004

6. Zhang YJ, Wei L, Li J, Zheng YQ and Li XR: Status quo and development trend of breast biopsy technology. Gland Surg 2: 15-24. 2013.

7. Hollingsworth MA and Swanson BJ: Mucins in cancer: Protection and control of the cell surface. Nat Rev Cancer 4: 45-60, 2004.

8. Nath S and Mukherjee P: MUC1: A multifaceted oncoprotein with a key role in cancer progression. Trends Mol Med 20: 332-342, 2014.

9. Duffy MJ, Shering S, Sherry F, McDermott E and O'Higgins N: CA 15-3: A prognostic marker in breast cancer. Int J Biol Markers 15: 330-333, 2000.

10. Harris LN, Ismaila N, McShane LM, Andre F, Collyar DE, Gonzalez-Angulo AM, Hammond EH, Kuderer NM, Liu MC, Mennel RG, et al: Use of biomarkers to guide decisions on adjuvant systemic therapy for women with early-stage invasive breast cancer: American society of clinical oncology clinical practice guideline. J Clin Oncol 34: 1134-1150, 2016.

11. Punyadeera $C$ and Slowey PD: Saliva as an emerging biofluid for clinical diagnosis and applications of MEMS/NEMS in salivary diagnostics. Nanobiomat Clin Dent, pp453-473, 2012.

12. Schafer CA, Schafer JJ, Yakob M, Lima P, Camargo P and Wong DT: Saliva diagnostics: Utilizing oral fluids to determine health status. Monogr Oral Sci 24: 88-98, 2014.
13. Bigler LR, Streckfus CF, Copeland L, Burns R, Dai X, Kuhn M, Martin P and Bigler SA: The potential use of saliva to detect recurrence of disease in women with breast carcinoma. J Oral Pathol Med 31: 421-431, 2002.

14. Li P, Ye H, Liu J, Jin H, Lin Y, Yan S, Yu Y, Gao L, Xu F and Zhang Z: Evaluation of a newly developed quantitative determination kit for tumor marker CA15-3 with chemiluminescent assay. J Clin Lab Anal 32, 2018.

15. Greene FL, Page DL, Fleming ID, Fritz AG, Balch CM, Haller DG and Morrow M (eds): AJCC Cancer Staging Manual. 7th edition, Sringer, 2017. https://cancerstaging.org/Pages/default.aspx

16. Goldhirsch A, Winer EP, Coates AS, Gelber RD, Piccart-Gebhart M, Thürlimann B and Senn HJ; Panel members: Personalizing the treatment of women with early breast cancer: Highlights of the St Gallen international expert consensus on the primary therapy of early breast cancer 2013. Ann Oncol 24: 2206-2223, 2013.

17. Victer TN, Dos Santos CS, Báo SN and Sampaio TL: Deceased tissue donor serology and molecular testing for HIV, hepatitis B and hepatitis $\mathrm{C}$ viruses: A lack of cadaveric validated tests. Cell Tissue Bank 17: 543-553, 2016.

18. Streckfus CF, Bigler L, Edwards C, Guajardo-Streckfus C and Bigler SA: Using saliva secretions to model disease progression. Adv Saliva Diagn, pp187-198, 2015.

19. Atoum M, Nimer N, Abdeldayem S and Nasr H: Relationships among serum CA15-3 tumor marker, TNM staging, and estrogen and progesterone receptor expression in benign and malignant breast lesions. Asian Pacific J Cancer Prev 13: 857-860, 2012.

20. Park S, Ahn HK, Park LC, Hwang DW, Ji JH, Maeng CH, Cho SH, Lee JY, Park KT, Ahn JS, et al: Implications of different CA 15-3 levels according to breast cancer subtype at initial diagnosis of recurrent or metastatic breast cancer. Oncology 82: 180-187, 2012.

21. Horm TM and Schroeder JA: MUC1 and metastatic cancer: Expression, function and therapeutic targeting. Cell Adhes Migr 7: 187-198, 2013.

22. Harris L, Fritsche H, Mennel R, Norton L, Ravdin P, Taube S, Somerfield MR, Hayes DF and Bast RC Jr; American Society of Clinical Oncology: American society of clinical oncology 2007 update of recommendations for the use of tumor markers in breast cancer. J Clin Oncol 25: 5287-5312, 2007.

23. Emens LA and Davidson NE: The follow-up of breast cancer. Semin Oncol 30: 338-348, 2003.

24. Agha-Hosseini F, Mirzaii-Dizgah I, Rahimi A and Seilanian-Toosi M: Correlation of serum and salivary CA125 levels in patients with breast cancer. J Contemp Dent Pract 10: E001-E008, 2009.

25. Kaczor-Urbanowicz KE, Martin Carreras-Presas C, Aro K, Tu M, Garcia-Godoy F and Wong DT: Saliva diagnostics-current views and directions. Exp Biol Med (Maywood) 242: 459-472, 2017.

26. Dawes C and Wong DTW: Role of saliva and salivary diagnostics in the advancement of oral health. J Dent Res 98: 133-141, 2019.

27. Meghnani V, Mohammed N, Giauque C, Nahire R and David T: Performance characterization and validation of saliva as an alternative specimen source for detecting hereditary breast cancer mutations by next generation sequencing. Int J Genomics 2016: 2059041, 2016

28. Cascella R, Stocchi L, Strafella C, Mezzaroma I, Mannazzu M, Vullo V, Montella F, Parruti G, Borgiani P, Sangiuolo F, et al: Comparative analysis between saliva and buccal swabs as source of DNA: Lesson from HLA-B*57:01 testing. Pharmacogenomics 16: 1039-1046, 2015.

This work is licensed under a Creative Commons Attribution-NonCommercial-NoDerivatives 4.0 International (CC BY-NC-ND 4.0) License. 